\title{
EVALUASI PENGURANGAN POLUSI UDARA AKIBAT OPTIMASI SIKLUS PADA SIMPANG BERSINYAL MENGGUNAKAN APLIKASI PTV VISSIM
}

\author{
Evaluation of Air Pollution Reduction Due to Cycle Time Optimization Using PTV \\ VISSIM Application
}

\author{
Siti Rahma ${ }^{1}$ dan Reza Asriandi Eka Putra ${ }^{1 *}$
}

${ }^{1}$ Institut Teknologi Sumatera, Jl. Terusan Ryacudu, Lampung Selatan, Indonesia

Informasi artikel
Diterima: 16/05/2019
Direvisi : 22/05/2019
Disetujui: 25/05/2019

\begin{abstract}
Abstrak
Lalu lintas merupakan penyumbang terbesar polusi udara perkotaan. Oleh karena itu diperlukaan perencanaan lalu lintas yang baik dalam mengurangi polusi udara. Salah satu cara yang dapat dilakukan adalah dengan efisiensi pergerakan simpang. Penelitian ini merencanakan pengelolaan simpang dengan optimasi pada cycle time. Penelitian ini bertujuan mengevaluasi besarnya pengurangan polusi akibat optimasi cycle time pada sebuah simpang dengan studi kasus Simpang Way Halim, Bandar Lampung. Evaluasi dilakukan dengan membandingkan pengurangan besaran emisi CO pada simpang bersinyal hasil Simulasi menggunakan PTV Vissim. Dari simulasi lalu lintas dihasilkan besar emisi CO pada 2019 sebesar 261.475gr CO dan 2024 adalah sebesar 349.453gr. Setelah optimasi, emisi CO tahun 2019 171.852gr sedangkan tahun 2024 sebesar 174.425gr CO. Kesimpulannya adalah pada dengan optimasi cycle time maka terjadi pengurangan emisi $\mathrm{CO}$ 2019 sebesar 34\% dari sedangkan pada tahun 2024 terjadi pengurangan CO sebesar $50 \%$.
\end{abstract}

Kata Kunci: Simpang bersinyal, karbon monoksida (CO), lalu lintas, optimasi, PTV Vissim.

\begin{abstract}
Traffic is one of the biggest contributors of urban air pollution. Consequently, good traffic planning is important to reduce air pollution. This research analyzes the effect of intersection cycle time optimization management. This study evaluates the pollution reduction due to cycle time optimization at an intersection WITH case study Way Halim, Bandar Lampung. Evaluation is proceeded by comparing the reduction of $\mathrm{CO}$ emissions at the intersection before optimization and after optimization using PTV Vissim. From the traffic simulation, the CO emissions in 2019 is $261.475 \mathrm{gr} C O$ and 2024 is $349.453 \mathrm{gr}$. After optimization, CO emissions in 2019 is 171,852 gr while in 2024 is $174.425 \mathrm{gr}$ CO. The conclusion is that with cycle time optimization there will be a reduction of CO 2019 emissions by 34\% and in 2024 there will be a reduction of CO by $50 \%$.
\end{abstract}

Keywords: Signalized intersection, carbon monoxide, traffic, optimization, PTV Vissim. 


\section{PENDAHULUAN}

Kota Bandar Lampung adalah sebuah kota dengan pergerakan manusia yang tinggi. Penggunaan transportasi menjadi sangat penting guna memenuhi kebutuhan masyarakat dan pengembangan terhadap suatu wilayah. Untuk mengetahui potensi perkembangan tersebut maka diperlukanya pendekatan modelling yang bervariasi bergantung tingkat kerincian perencanaanya (Ehlert. 2017) Penggunaan kendaraan bermotor sebagai alat pemenuh kebutuhan dapat memberikan dampak positif dan dampak negatif. Jika hal ini tidak diimbangi dengan kemampuan suatu ruas jalan untuk menampung pergerakan transportasi yang terjadi, maka akan timbul kemacetan pada ruas jalan tersebut (Hobbs. 1995). Oleh karena itu perlunya dilakukan model lalu lintas sebagai representasi dari karakteristik lalu lintas (Noland. 2006). Kemacetan lalu lintas merupakan suatu masalah yang hingga saat ini masih dialami di wilayah Kota Bandar Lampung yang diperkirakan akan semakin bertambah jika tidak ditangani dengan baik. Kerugian yang ditimbulkan akibat kemacetan lalu lintas selain kerugian waktu dan biaya adalah kerugian akibat polusi udara.

Seiring dengan peningkatan lalu lintas, dampak negatif yang terjadi salah satunya adalah meningkatnya kadar emisi gas buang kendaraan. Pergerakan kendaraan ini menimbulkan peningkatan terhadap penggunaan bahan bakar minyak dan mempengaruhi pencemaran udara. Timbulnya zat-zat berbahaya yang ditimbulkan dari gas buang kendaraan akibat kemacetan lalu lintas tentu akan menjadi permasalahan baru yang serius di perkotaan. Kota Bandar Lampung yang menjadi salah satu motor penggerak pembangunan ekonomi di Indonesia sudah selayaknya melakukan pemantauan kualitas udara yang dihasilkan dari kendaraan bermotor agar dapat selalu menjaga kualitas udara pada kondisi yang baik.

Secara umum pencemar udara dibagi atas pencemar primer dan pencemar sekunder. Pencemar primer adalah zat-zat yang diemisikan langsung dari suatu proses, seperti abu vulkanik dari letusan gunung berapi, knalpot kendaraan bermotor, atau zat yang diemisikan dari cerobong pabrik. Pencemar sekunder adalah pencemar yang tidak langsung diemisikan dari suatu proses, melainkan terbentuk di udara ketika pencemar-pencemar primer bereaksi atau berinteraksi. Zat berbahaya yang ditimbulkan dari kendaraan bermotor antara lain karbon monoksida (CO) dan nitrogen oksida (NOx). Terdapat lebih dari $75 \%$ gas karbon monoksida (CO) dihasilkan oleh kendaraan bermotor. Emisi CO umumnya meningkat saat terjadi kemacetan di jalan dan tergolong gas yang beracun dan mematikan. Konsentrasi CO di udara ambien sebesar 200 ppm selama 7 jam dapat menyebabkan pusing-pusing pada manusia yang tidak melakukan kegiatan fisik dan 2 jam pada manusia yang melakukan kegiatanH fisik berat seperti berolahraga. Sedangkan pada konsentrasi 400 ppm selama 2 jam atau 45 menit pada manusia yang melakukan aktivitas fisik yang berat dapat menyebabkan hilangnya kesadaran. Sedangkan NOx terjadi ketika bahan bakar kendaraan terbakar pada suhu tinggi. NOx dikategorikan dalam dua kategori yaitu NO termal dan NO bahan bakar. NO bahan bakar merupakan NO yang berasal dari kandungan nitrogen dalam bahan bakar. Emisi NO bahan bakar dapat menimbulkan gangguan pada kesehatan pernapasan, radang paru-paru, bahkan kematian. Selain itu, dampak NOx pada lingkungan yaitu hujan asam yang ditimbulkan dari reaksi antara NOx dan senyawa-senyawa lain, pemanasan global yang disebabkan oleh salah satu spesies NOx yaitu nitrous oksida atau dinitrogen monoksida (N2O), Berkurangnya jarak pandang yang disebabkan oleh partikel nitrat dan NO2. Partikel nitrat dan NO2 mampu menghalangi transmisi cahaya dan membentuk kabut sehingga mengganggu pemandangan. Emisi ini timbul akibat pembakaran yang tidak sempurna, perawatan kendaraan yang kurang memadai, dan penggunaan kualitas bahan bakar yang tidak baik.

Pencemaran udara akibat lalu lintas ini dapat dikurangi dengan pendekatan ekstensifikasi atau intensifikasi. Metode ekstensifikasi dapat dilakukan dengan mengurangi jumlah kendaraan yang melakukan pergerakan di jalan raya, salah satunya ada;ah dengan penggunaan transportasi public. Sedangkan pendekatan intensifikasi dengan mengefisienkan pergerakan di dalam lalu lintas tersebut, salahsatunya mengefisienkan pergerakan di lampu merah. Berdasarkan penjelasan di atas, maka dilakukan penelitian Evaluasi Pengurangan Polusi Udara Akibat Optimasi Cycle Time Pada Simpang Bersinyal Menggunakan Aplikasi PTV Vissim dilakukan dengan tujuan: 
1. Mengumpulkan data lalu lintas pada simpang Way Halim Kota Bandar Lampung;

2. Melakukan simulasi, optimasi dan forecast pada simpang Way Halim Kota Bandar Lampung;

3. Melakukan analisis parameter emisi CO pada hasil simulasi simpang, optimasi dan forecast.

\section{METODOLOGI}

Dalam pelaksanaan penelitian ini, dilaksanakan traffic modelling menggunakan aplikasi PTV Vissim. Dalam traffic modelling yang tersebut, data-data hasil survey lalu lintas dan cycle time menjadi dasar dalam pembentukan model transportasi. Atas dasar tersebut maka terdapat beberapa tahapan yang perlu dikerjakan dalam proses menyelesaikan model untuk di analisis.

Pengumpulan data primer merupakan pengumpulan data lapangan. Dalam penelitian yang dilaksanakan teerdapat tiga buah data primer yang dikumpulkan yaitu data arus lalu lintas, data geometri jalan, serta data green time pada setiap lengan simpang. Ketiga data ini merupakan data yang diinput ke dalam model untuk mengetahui kinerja simpang serta pada akhirnya untuk mengetahui potensi pencemaran udara akibat lalu lintas.

Dari data-data tersebut dibentuk model transportasi primer berdasarkan data eksisting. Dari model primer tersebut diperoleh indicator pencemaran lingkungan. Selanjutnya dilakukan optimasi persimpangan dengan menggunakan tools optimized all fixed time, sehingga diperoleh cycle time yang merupakan hasil optimasi simpang. Analisis yang dilaksanakan adalah dengan mengevaluasi besarnya perubahan tingkat polusi udara akibat optimasi cycle time.

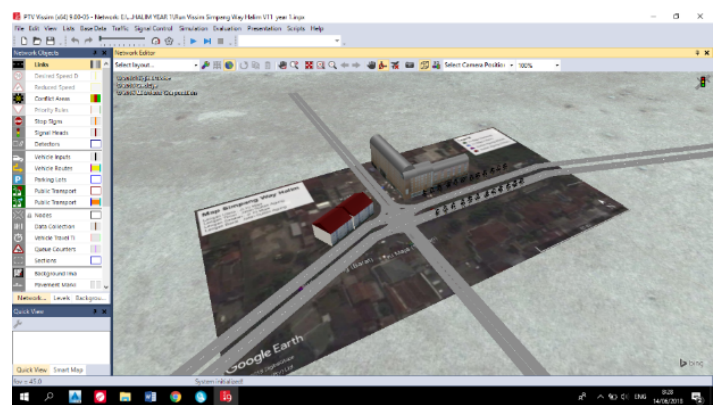

Gambar 1 Model PTV Vissim

\section{HASIL DAN PEMBAHASAN}

Pada bagian ini akan disampaikan hasil dan pembahasan dari penelitian yang telah dilaksanakan. Hasil penelitian yang dimaksud adalah hasil pengumpulan data primer, hasil tingkat pencemaran udara dari model primer dan dioptimasi pada tahun 2019, serta hasil pencemaran udara dari model primer dan model optimasi pada tahun 2024.

\section{Hasil Pengumpulan Data Primer}

Hasil pengumpulan data primer meliputi 3 (tiga) buah data yaitu:

1. Geometri Simpang

2. Cycle Time

3. Arus Lalu Lintas

Lokasi yang ditinjau adalah simpang Way Halim, Kota Bandar Lampung, provinsi lampung. Karakteristik simpang yang ditinjau adalah Pendekat Barat dan Timur bertipe 4/2 D sedangkan pendekat utara dan selatan bertipe 2/2 UD. Pendekat barat dan timur merupakan jalur utama penghubung antara Kecamatan Sukarame menuju Kecamatan Rajabasa. Geometri simpang yang diperoleh dari survey lapangan disajikan pada Gambar 2 .

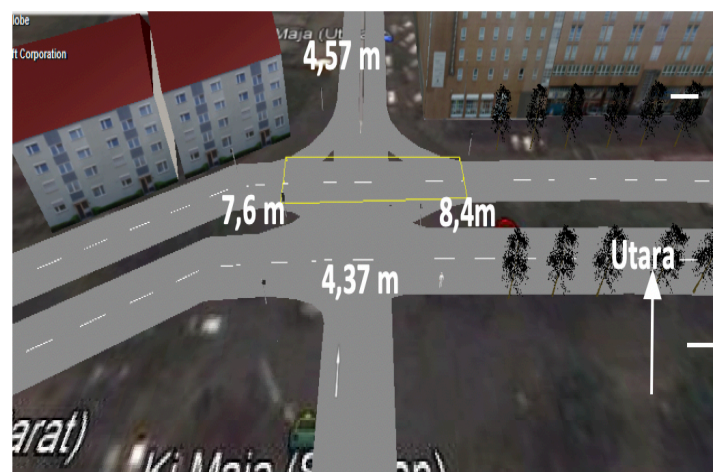

Gambar 2 Gambar Geometri Jalan (Putra.2018)

Cycle Time pada simpang Way Halim terbagi kedalam 4 fase. Setiap fase memfasilitasi pergerakan dari satu buah lengan simpang. Fase 1 merupakan pergerakan dari timur dengan Waktu Hijau selama 37 detik. Selanjutnya adalah pergerakan dari pendekat barat dengan waktu hijau 30 detik. Setelah itu adalah Pendekat Selatan dengan waktu hijau selama 47 detik dan terakhir adalah pendekat utara dengan waktu hijau selama 23 detik. Tahapan fase dalam cycle time pada simpang yang ditinjau disajikan pada Gambar 3. 


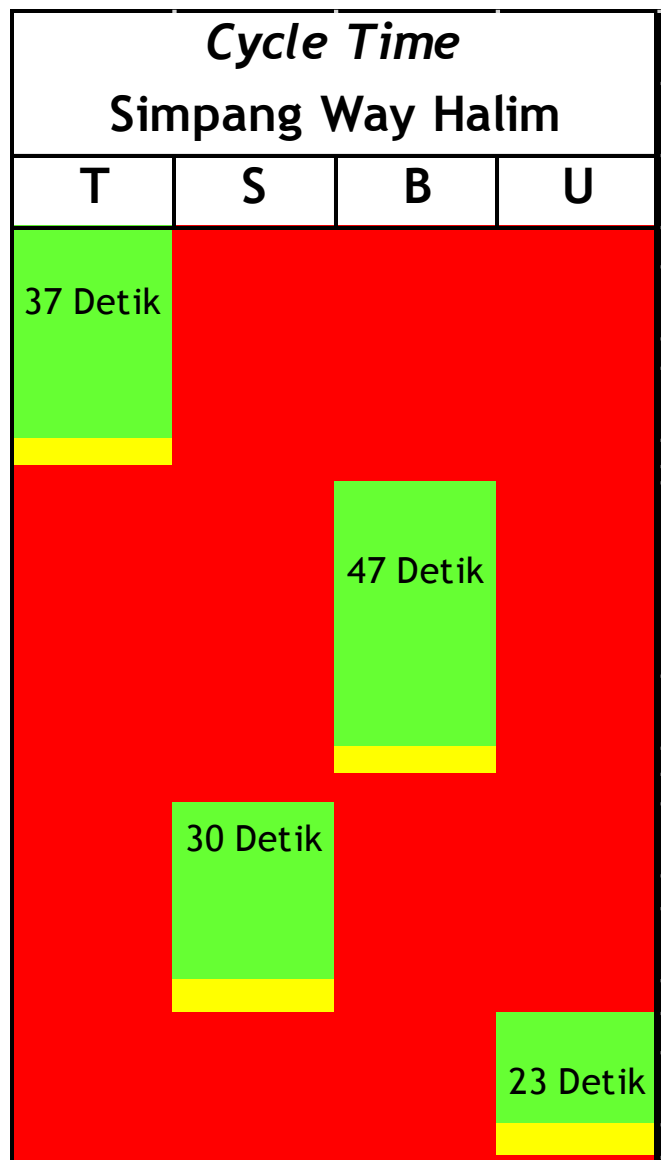

Gambar 3. Green Time Simpang Way Halim

Sedangkan data arus lalu lintas yang diperoleh pada studi yang dilaksanakan disajikan pada Tabel 1.

\section{Model Eksisting Tahun 2019 dan 2024}

Model eksisting 2019 adalah model yang dibentuk berdasarkan data primer sedangkan data tahun 2024 merupakan hasil forecasting volume lalu lintas pada tahun 2024. Pada penelitian ini parameter kinerja yang diperoleh dari model adalah kinerja lingkungan dari simpang yaitu besaran emisi CO yang disajikan pada Tabel 2. Dari hasil simulasi kondisi tahun 2019 total emisi yang dihasilkan dari semua pergerakan pada lengan simpang adalah 261.476 gr sedangkan pada tahun 2024 adalah 349.453 gr.

\section{Model Optimasi}

Model optimasi merupakan model yang dibangun dengan cara mengoptimalkan green time dengan bantuan aplikasi PTV Vissim. Pad astudi ini terdapat waktu model optimasi yaitu pada tahun 2019 dan pada tahun 2024. Hasil model optimasi ini menghasilkan cycle time yang baru yang disajikan pada Gambar
4. Dari hasil optimasi diperoleh waktu hijau untuk pendekat timur adalah 46 detik, pendekat barat 39 detik, pendekat selatan 22 detik, dan pendekat utara adalah 30 detik.

Tabel 1. Data arus lalu lintas

\begin{tabular}{ccccc}
\hline \multirow{3}{*}{$\begin{array}{cccc}\text { Pendekat } \\
\text { Arah }\end{array}$} & \multicolumn{3}{c}{ Volume } \\
\cline { 3 - 5 } & & Mendaraan/Jam) & LV & HV \\
\hline \multirow{3}{*}{ U } & ST & 941 & 168 & 15 \\
& LT & 388 & 106 & 4 \\
& RT & 161 & 70 & 0 \\
\hline \multirow{3}{*}{ S } & ST & 745 & 134 & 23 \\
& LT & 359 & 136 & 0 \\
& RT & 161 & 59 & 0 \\
\hline \multirow{3}{*}{ T } & ST & 737 & 400 & 10 \\
& LT & 332 & 96 & 3 \\
& RT & 192 & 149 & 7 \\
\hline \multirow{3}{*}{ B } & ST & 1019 & 214 & 15 \\
& LT & 210 & 141 & 6 \\
& RT & 210 & 141 & 6 \\
\hline
\end{tabular}

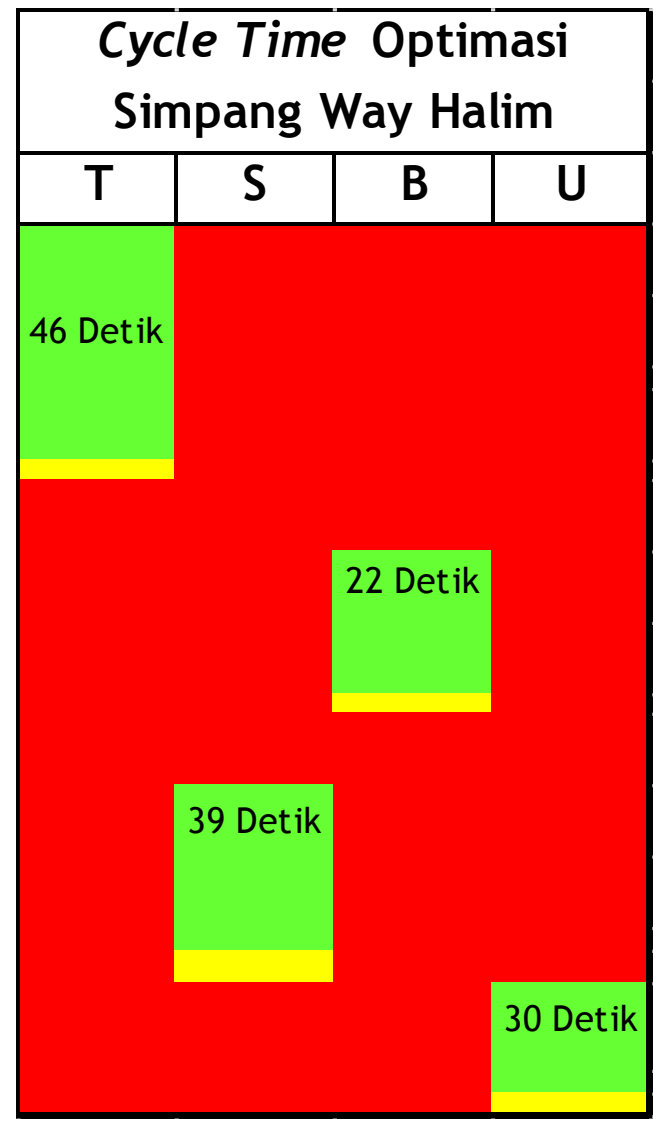

Gambar 4 Green Time Optimasi 
Tabel 2 Emisi CO model eksisting 2019 Eksisting

\begin{tabular}{|c|c|c|c|}
\hline Movement & $\begin{array}{l}\text { Qlen } \\
(\mathrm{m})\end{array}$ & $\begin{array}{l}\text { Delay } \\
\text { (s) }\end{array}$ & $\begin{array}{c}\mathrm{CO} \\
\text { (gr/h) }\end{array}$ \\
\hline $\begin{array}{l}\text { Jl. Ki Maja (Utara)- Jl. } \\
\text { Sultan Agung } \\
\text { (Barat)@433.9 }\end{array}$ & 198 & 338 & 12.33 \\
\hline $\begin{array}{l}1 \text { - 1: Jl. Ki Maja } \\
\text { (Utara)@3.5 - 10: Jl. Ki } \\
\text { Maja (Timur)@412.3 }\end{array}$ & 198 & 329 & 6.12 \\
\hline $\begin{array}{l}1 \text { - 1: Jl. Ki Maja } \\
\text { (Utara)@3.5 - 12: Jl. Ki } \\
\text { Maja (Selatan)@267.3 }\end{array}$ & 198 & 341 & 17.37 \\
\hline $\begin{array}{l}1 \text { - 2: Jl. Sultan Agung } \\
\text { (Barat)@24.6 - 10: Jl. } \\
\text { Ki Maja (Timur)@412.3 }\end{array}$ & 340 & 506 & 79.30 \\
\hline $\begin{array}{l}\text { - 2: Jl. Sultan Agung } \\
\text { (Barat)@24.6 - 11: Jl. } \\
\text { Ki Maja (Utara)@227.5 }\end{array}$ & 340 & 529 & 16.17 \\
\hline $\begin{array}{l}1 \text { - 2: Jl. Sultan Agung } \\
\text { (Barat)@24.6 - 12: Jl. } \\
\text { Ki Maja } \\
\text { (Selatan)@267.3 }\end{array}$ & 340 & 498 & 17.04 \\
\hline $\begin{array}{l}1 \text { - 3: Jl. Ki Maja } \\
\text { (Timur)@10.1 - 9: Jl. } \\
\text { Sultan Agung } \\
\text { (Barat)@433.9 }\end{array}$ & 331 & 553 & 26.15 \\
\hline $\begin{array}{l}\text { 1 - 3: Jl. Ki Maja } \\
\text { (Timur)@10.1 - 11: Jl. } \\
\text { Ki Maja (Utara)@227.5 }\end{array}$ & 331 & 576 & 11.98 \\
\hline $\begin{array}{l}\text { - 3: Jl. Ki Maja } \\
\text { (Timur)@10.1 - 12: Jl. } \\
\text { Ki Maja } \\
\text { (Selatan)@267.3 }\end{array}$ & 331 & 583 & 66.73 \\
\hline $\begin{array}{l}1 \text { - 4: Jl. Ki Maja } \\
\text { (Selatan)@14.3 - 9: Jl. } \\
\text { Sultan Agung } \\
\text { (Barat)@433.9 }\end{array}$ & 50 & 52 & 2.37 \\
\hline $\begin{array}{l}1 \text { - 4: Jl. Ki Maja } \\
\text { (Selatan)@14.3 - 10: } \\
\text { Jl. Ki Maja } \\
\text { (Timur)@412.3 }\end{array}$ & 50 & 53 & 4.18 \\
\hline $\begin{array}{l}1 \text { - 4: Jl. Ki Maja } \\
\text { (Selatan)@14.3 - 11: } \\
\text { Jl. Ki Maja } \\
\text { (Utara)@227.5 }\end{array}$ & 50 & 50 & 1.73 \\
\hline
\end{tabular}

2024 Eksisting

\begin{tabular}{|c|c|c|c|}
\hline Movement & $\begin{array}{l}\text { Qlen } \\
(\mathrm{m})\end{array}$ & $\begin{array}{l}\text { Delay } \\
\text { (s) }\end{array}$ & $\begin{array}{c}\mathrm{CO} \\
(\mathrm{gr} / \mathrm{h})\end{array}$ \\
\hline $\begin{array}{l}\text { 1 - 1: Jl. Ki Maja } \\
\text { (Utara)@3.5 - 9: Jl. } \\
\text { Sultan Agung } \\
\text { (Barat)@433.9 }\end{array}$ & 201 & 337 & 12.56 \\
\hline $\begin{array}{l}1 \text { - 1: Jl. Ki Maja } \\
\text { (Utara)@3.5 - 10: Jl. Ki } \\
\text { Maja (Timur)@412.3 }\end{array}$ & 201 & 329 & 6.65 \\
\hline $\begin{array}{l}1 \text { - 1: Jl. Ki Maja } \\
\text { (Utara)@3.5 - 12: Jl. Ki } \\
\text { Maja (Selatan)@267.3 }\end{array}$ & 201 & 339 & 16.86 \\
\hline $\begin{array}{l}1 \text { - 2: Jl. Sultan Agung } \\
\text { (Barat)@24.6 - 10: Jl. } \\
\text { Ki Maja (Timur)@412.3 }\end{array}$ & 402 & 607 & 98.44 \\
\hline $\begin{array}{l}1 \text { - 2: Jl. Sultan Agung } \\
\text { (Barat)@24.6 - 11: Jl. } \\
\text { Ki Maja (Utara)@227.5 }\end{array}$ & 402 & 634 & 20.69 \\
\hline $\begin{array}{l}\text { 1 - 2: Jl. Sultan Agung } \\
\text { (Barat)@24.6 - 12: Jl. } \\
\text { Ki Maja } \\
\text { (Selatan)@267.3 }\end{array}$ & 402 & 616 & 22.05 \\
\hline $\begin{array}{l}1 \text { - 3: Jl. Ki Maja } \\
\text { (Timur)@10.1 - 9: Jl. } \\
\text { Sultan Agung } \\
\text { (Barat)@433.9 }\end{array}$ & 380 & 699 & 36.81 \\
\hline $\begin{array}{l}\text { 1 - 3: Jl. Ki Maja } \\
\text { (Timur)@10.1 - 11: Jl. } \\
\text { Ki Maja (Utara)@227.5 }\end{array}$ & 380 & 710 & 14.99 \\
\hline $\begin{array}{l}1 \text { - 3: Jl. Ki Maja } \\
\text { (Timur)@10.1 - 12: Jl. } \\
\text { Ki Maja } \\
\text { (Selatan)@267.3 }\end{array}$ & 380 & 700 & 83.33 \\
\hline $\begin{array}{l}1 \text { - 4: Jl. Ki Maja } \\
\text { (Selatan)@14.3 - 9: Jl. } \\
\text { Sultan Agung } \\
\text { (Barat)@433.9 }\end{array}$ & 183 & 145 & 10.75 \\
\hline $\begin{array}{l}1 \text { - 4: Jl. Ki Maja } \\
\text { (Selatan)@14.3 - 10: } \\
\text { Jl. Ki Maja } \\
\text { (Timur)@412.3 }\end{array}$ & 183 & 145 & 17.89 \\
\hline $\begin{array}{l}1 \text { - 4: Jl. Ki Maja } \\
\text { (Selatan)@14.3 - 11: } \\
\text { Jl. Ki Maja } \\
\text { (Utara)@227.5 }\end{array}$ & 183 & 146 & 8.42 \\
\hline
\end{tabular}


Tabel 3. Emisi CO model optimasi

2019 Optimasi

\begin{tabular}{|c|c|c|c|}
\hline Movement & $\begin{array}{l}\text { Qlen } \\
(\mathrm{m})\end{array}$ & $\begin{array}{c}\text { Delay } \\
\text { (s) }\end{array}$ & $\begin{array}{c}\mathrm{CO} \\
(\mathrm{gr} / \mathrm{h})\end{array}$ \\
\hline $\begin{array}{l}\text { 1 - 1: Jl. Ki Maja } \\
\text { (Utara)@3.5 - 9: Jl. } \\
\text { Sultan Agung } \\
\text { (Barat)@433.9 }\end{array}$ & 191 & 289 & 11.81 \\
\hline $\begin{array}{l}\text { 1 - 1: Jl. Ki Maja } \\
\text { (Utara)@3.5 - 10: } \\
\text { Jl. Ki Maja } \\
\text { (Timur)@412.3 }\end{array}$ & 191 & 292 & 6.73 \\
\hline $\begin{array}{l}\text { 1 - 1: Jl. Ki Maja } \\
\text { (Utara)@3.5 - 12: } \\
\text { Jl. Ki Maja } \\
\text { (Selatan)@267.3 }\end{array}$ & 191 & 293 & 15.37 \\
\hline $\begin{array}{l}1 \text { - 2: Jl. Sultan } \\
\text { Agung } \\
\text { (Barat)@24.6 - 10: } \\
\text { Jl. Ki Maja } \\
\text { (Timur)@412.3 }\end{array}$ & 169 & 210 & 24.35 \\
\hline $\begin{array}{l}1 \text { - 2: Jl. Sultan } \\
\text { Agung } \\
\text { (Barat)@24.6 - 11: } \\
\text { Jl. Ki Maja } \\
\text { (Utara)@227.5 }\end{array}$ & 169 & 205 & 4.05 \\
\hline $\begin{array}{l}\text { 1 - 2: Jl. Sultan } \\
\text { Agung } \\
\text { (Barat)@24.6 - 12: } \\
\text { Jl. Ki Maja } \\
\text { (Selatan)@267.3 }\end{array}$ & 169 & 195 & 4.52 \\
\hline $\begin{array}{l}\text { 1 - 3: Jl. Ki Maja } \\
\text { (Timur)@10.1 - 9: } \\
\text { Jl. Sultan Agung } \\
\text { (Barat)@433.9 }\end{array}$ & 255 & 334 & 16.41 \\
\hline $\begin{array}{l}\text { 1 - 3: Jl. Ki Maja } \\
\text { (Timur)@10.1 - 11: } \\
\text { Jl. Ki Maja } \\
\text { (Utara)@227.5 }\end{array}$ & 255 & 335 & 7.03 \\
\hline $\begin{array}{l}\text { 1 - 3: Jl. Ki Maja } \\
\text { (Timur)@10.1 - 12: } \\
\text { Jl. Ki Maja } \\
\text { (Selatan)@267.3 }\end{array}$ & 255 & 355 & 41.10 \\
\hline $\begin{array}{l}1 \text { - 4: Jl. Ki Maja } \\
\text { (Selatan)@14.3 - 9: } \\
\text { Jl. Sultan Agung } \\
\text { (Barat)@433.9 }\end{array}$ & 213 & 255 & 11.02 \\
\hline $\begin{array}{l}\text { - 4: Jl. Ki Maja } \\
\text { (Selatan)@14.3 - } \\
\text { 10: Jl. Ki Maja } \\
\text { (Timur)@412.3 }\end{array}$ & 213 & 263 & 18.79 \\
\hline $\begin{array}{l}\text { - 4: Jl. Ki Maja } \\
\text { (Selatan)@14.3 - } \\
\text { 11: Jl. Ki Maja } \\
\text { (Utara)@227.5 }\end{array}$ & 213 & 266 & 10.68 \\
\hline
\end{tabular}

2024 Optimasi

\begin{tabular}{|c|c|c|c|}
\hline Movement & $\begin{array}{l}\text { Qlen } \\
(\mathrm{m})\end{array}$ & $\begin{array}{l}\text { Delay } \\
\text { (s) }\end{array}$ & $\begin{array}{c}\mathrm{CO} \\
(\mathrm{gr} / \mathrm{h})\end{array}$ \\
\hline $\begin{array}{l}\text { 1 - 1: Jl. Ki Maja } \\
\text { (Utara)@3.5 - 9: } \\
\text { Jl. Sultan Agung } \\
\text { (Barat)@433.9 }\end{array}$ & 123 & 114 & 7.44 \\
\hline $\begin{array}{l}\text { 1 - 1: Jl. Ki Maja } \\
\text { (Utara)@3.5 - 10: } \\
\text { Jl. Ki Maja } \\
\text { (Timur)@412.3 }\end{array}$ & 123 & 108 & 3.78 \\
\hline $\begin{array}{l}\text { 1 - 1: Jl. Ki Maja } \\
\text { (Utara)@3.5 - 12: } \\
\text { Jl. Ki Maja } \\
\text { (Selatan)@267.3 }\end{array}$ & 123 & 120 & 10.30 \\
\hline $\begin{array}{l}1 \text { - 2: Jl. Sultan } \\
\text { Agung } \\
\text { (Barat)@24.6 - } \\
\text { 10: Jl. Ki Maja } \\
\text { (Timur)@412.3 }\end{array}$ & 385 & 355 & 45.70 \\
\hline $\begin{array}{l}1 \text { - 2: Jl. Sultan } \\
\text { Agung } \\
\text { (Barat)@24.6 - } \\
\text { 11: Jl. Ki Maja } \\
\text { (Utara)@227.5 }\end{array}$ & 385 & 367 & 9.83 \\
\hline $\begin{array}{l}1 \text { - 2: Jl. Sultan } \\
\text { Agung } \\
\text { (Barat)@24.6 - } \\
\text { 12: Jl. Ki Maja } \\
\text { (Selatan)@267.3 }\end{array}$ & 385 & 357 & 10.23 \\
\hline $\begin{array}{l}\text { 1 - 3: Jl. Ki Maja } \\
\text { (Timur)@10.1 - 9: } \\
\text { Jl. Sultan Agung } \\
\text { (Barat)@433.9 }\end{array}$ & 379 & 550 & 18.10 \\
\hline $\begin{array}{l}1 \text { - 3: Jl. Ki Maja } \\
\text { (Timur)@10.1 - } \\
\text { 11: Jl. Ki Maja } \\
\text { (Utara)@227.5 }\end{array}$ & 379 & 541 & 5.75 \\
\hline $\begin{array}{l}1 \text { - 3: Jl. Ki Maja } \\
\text { (Timur)@10.1 - } \\
\text { 12: Jl. Ki Maja } \\
\text { (Selatan)@267.3 }\end{array}$ & 379 & 546 & 37.51 \\
\hline $\begin{array}{l}\text { 1 - 4: Jl. Ki Maja } \\
\text { (Selatan)@14.3 - } \\
\text { 9: Jl. Sultan } \\
\text { Agung } \\
\text { (Barat)@433.9 }\end{array}$ & 238 & 253 & 7.18 \\
\hline $\begin{array}{l}1 \text { - 4: Jl. Ki Maja } \\
\text { (Selatan)@14.3 - } \\
\text { 10: Jl. Ki Maja } \\
\text { (Timur)@412.3 }\end{array}$ & 238 & 250 & 12.88 \\
\hline $\begin{array}{l}1 \text { - 4: Jl. Ki Maja } \\
\text { (Selatan)@14.3 - } \\
\text { 11: Jl. Ki Maja } \\
\text { (Utara)@227.5 }\end{array}$ & 238 & 247 & 5.73 \\
\hline
\end{tabular}


Dari data yang disajikan terdapat peningkatan parameter emisi $\mathrm{CO}$ akibat peningkatan traffic pada jaringan jalan yang ditinjau. Selanjutnya dilakukan optimasi pada simpang sehingga menghasilkan dapat diketahui parameter emisi yang terjadi. Data hasil optimasi disajikan pada Tabel 3.

Dari kedua tabel yang dihasilkan dari simulasi dengan meggunakan aplikasi PTV Vissum terdapat perbedaan yang signifikan. Sebagai contoh pada tabel 2, untuk emisi CO model eksisting tahun 2019 pada movement Jl. Ki Maja (Utara)- Jl. Sultan Agung (Barat)@433.9 sebesar $12.33 \mathrm{gr} / \mathrm{h}$ dan pada model eksisting tahun 2024 pada movement yang sama, yaitu Jl. Ki Maja (Utara)- Jl. Sultan Agung (Barat)@433.9 sebesar 12.56 $\mathrm{gr} / \mathrm{h}$. Sedangkan pada tabel 3, untuk emisi CO model optimasi tahun 2019 pada movement Jl. Ki Maja (Utara)- Jl. Sultan Agung (Barat)@433.9 sebesar $11.81 \mathrm{gr} / \mathrm{h}$ dan pada model eksisting tahun 2024 pada movement yang sama, yaitu Jl. Ki Maja (Utara)- Jl. Sultan Agung (Barat)@433.9 sebesar $7.44 \mathrm{gr} / \mathrm{h}$. Berdasarkan contoh diatas terdapat perbedaan yang cukup signifikan antara data model eksisting dengan data model optimasi dengan menggunakan aplikasi PTV Vissum.

\section{Analisis}

Model simpang hasil optimasi menghasilkan signifikansi dampak yang berbeda pada kondisi tahun 2019 dan 2024. Data hasil optimasi dibandingkan dengan sebelum dioptimasi disajikan pada Tabel 4.

Tabel 4 Perbandingan Model Sebelum dan Sesudah Optimasi

\begin{tabular}{cccc}
\hline No & Jenis Model & CO & Perubahan \\
\hline & $\begin{array}{c}\text { Model 2019 } \\
\text { Eksisting } \\
\text { Model 2019 } \\
\text { Optimasi }\end{array}$ & 261.476 & \\
& 171.852 & $34 \%$ \\
\hline & $\begin{array}{c}\text { Model 2024 } \\
\text { Eksisting } \\
\text { Model 2024 } \\
\text { Optimasi }\end{array}$ & 349.453 & $50 \%$ \\
\hline
\end{tabular}

Dari Tabel 4 diperoleh informasi bahwa persimpangan yang mengalami optimasi cycle time akan mengalami penurunan emisi $\mathrm{CO}$. Pada kondisi tahun 2019 terjadi penurunan dari 261.476 gr menjadi 171.852 gr atau sebesar $34 \%$ sedangkan pada model tahun 2024 terjadi penurunan emisi CO dari 349.453 gr menjadi 174.425 atau sebesar $50 \%$. Dari informasi tersebut diperkirakan bahwa semakin tinggi arus lalu lintas maka akan semakin besar pengaruh dari optimasi persimpangan tersebut.

\section{SIMPULAN}

Berdasarkan hasil pembahasan dan Analisa simulasi dapat disimpulkan, bahwa pada simpang yang ditinjau dari hasil estimasi pergerakan maka diperoleh pergerakan yang bervariasi dari setiap lengan yaitu pada pendekat Utara adalah 1853 kendaraa/jam, Selatan 1616 kendaraan/jam, Timur, 1926 kendaraan/jam, dan barat 2207 kendaraan/jam.

Pada studi ini dilakukan optimasi cycle time pada dengan green time pada lengan timur adalah 37 detik, lengan barat 30 detik, lengan selatan 47 detik, dan lengan utara 23 detik. Setalah dilakukan optimasi diperolah gren time pada lengan timur adalah 46 detik, lengan barat 39 detik, lengan selatan 22 dtik dan lengan utara 30 detik.

Dari hasil simulasi diperoleh emisi gas sebesar 261.476 gr pada tahun 2019 serta setelah di proyeksikan maka tahun 2024 akan menghasilkan $349.453 \mathrm{gr} \mathrm{CO}$, sedangkan hasil optimasi adalah 171.852 gr dan 174.425 gr pada tahun 2019 dan 2024. Hasil simulasi baik kondisi eksisting ataupun forecast terjadi penuruan emisi CO sebesar 34\% pada kondisi eksisting dan $50 \%$ pada saat kondisi forecast.

Dari hasil pemodelan yang dilaksanakan dapat disimpulkan bahwa optimasi waktu siklus pada sebuah simpang dapat mengurangi besaran emisi CO pada sebuah simpang yang besarnya bervariasi

\section{UCAPAN TERIMA KASIH}

Ucapan terimakasih kami sampaikan kepada Lembaga Penelitian, Pengebdian Kepada Masyarakat, dan Penjaminan Mutu Institut Teknologi Sumatera selaku penyandang dana penelitian yang dilaksanakan. Juga Program Studi Teknik Sipil Institut Teknologi Sumatera selaku pemilik aplikasi resmi PTV Vissum dan PTV Vissim yang menjadi sumber data serta digunakan dalam penelitian. Juga rekan-rekan sejawat tenaga pengajar dan mahasiswa Institut Teknologi Sumatera yang telah membantu melaksanakan pengumpulan data dalam penelitian yang dilaksanakan. 


\section{DAFTAR PUSTAKA}

Direktorat Jenderal Binamarga, 1997. Manual Kapasitas Jalan (MKJI), Jakarta: Departemen Pekerjaan Umum.

Ehlert A., 2017. Junction parameter calibration for mesoscopic simulation in Vissim. in nternational Symposia of Transport Simulation (ISTS) and the International Workshop on Traffic Data Collection and its Standardization (IWTDCS): Advanced Transport Simulation Modelling based on Big Data. pp.216-226.

Hobbs, F. D., 1995. Traffic Planning and Engineering, Second Edition. Oxford : Pergamon.

Noland, R.B., 2005. Flow improvements and vehicle emissions: Effects of trip generation and emission control technology. Transportation Research Part D, 11(1). pp.1-14.

PTV VISION, 2014. PTV VISSIM - New Fitures at a glance". Karlsruhe: PTV AG.

Putra R.A.E. 2018, Optimasi Green Time Simpang Bersinyal dengan Menggunakan PTV Vissim dalam Meningkatkan Kinerja Simpang (Studi Kasus: Simpang Way Halim Bandar Lampung). Jurnal Teoretis dan Terapan Bidang Rekayas Sipil, 6(2), pp. 108-118.

Sonny I., 2015. Simulasi Model Kinerja Pelayanan Ruas Jalan di Jakarta Menggunakan Aplikasi Vissim Studi Ruas Jalan Diponegoro. Warta Penelitian Perhubungan, 27 (2). Pp.110.

Tamin, O.Z., 2010. Perencanaan dan Pemodelan Transportasi. Bandung : Penerbit ITB. 